\title{
Wetting Behavior of Selected Crude Oil/Brine/Rock Systems
}

\author{
Topical Report
}

\author{
March 1, 1994 - March 31, 1995
}

Work Performed Under Contract No.: DE-FC21-93MC30127

\author{
For \\ U.S. Department of Energy \\ Office of Fossil Energy \\ Morgantown Energy Technology Center \\ P.O. Box 880
}

Morgantown, West Virginia 26507-0880

\section{By}

Western Research Institute

365 North Ninth Street

Laramie, Wyoming 82070 


\section{Disclaimer}

This report was prepared as an account of work sponsored by an agency of the United States Government. Neither the United States Government nor any agency thereof, nor any of their employees, makes any warranty, express or implied, or assumes any legal liability or responsibility for the accuracy, completeness, or usefulness of any information, apparatus, product, or process disclosed, or represents that its use would not infringe privately owned rights. Reference herein to any specific commercial product, process, or service by trade name, trademark, manufacturer, or otherwise does not necessarily constitute or imply its endorsement, recommendation, or favoring by the United States Government or any agency thereof. The views and opinions of authors expressed

herein do not necessarily state or reflect those of the United States Government or any agency thereof. 


\section{ACKNOWLEDGE MENTS}

This work was supported by Arco, British Petroleum, Chevron, Conoco, ELF, Mobil, Norsk Hydro, Shell, Statoil, the Western Research Institute (WRI) DOE J ointly Sponsored Research Program, and the Enhanced Oil Recovery Institute (EORI) of the University of Wyoming. 


\section{TABLE OF CONTENTS}

Page

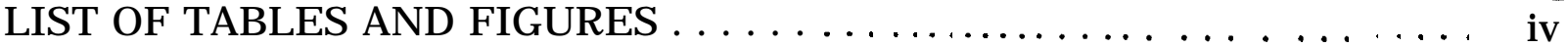

EXECUTIVE SUMMARY $\ldots \ldots \ldots \ldots \ldots \ldots \ldots \ldots$

INTRODUCTION ............................. 1

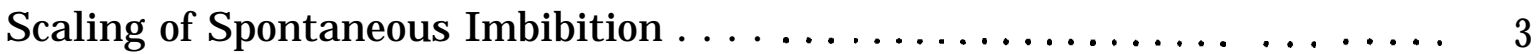

Imbibition by Crude Oil/Brine/Rock Systems . . . . . . . . . . . . . . . 3

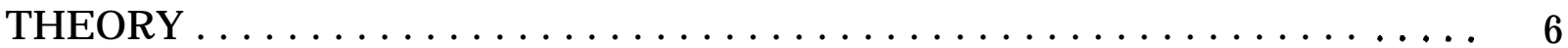

Imbibition Rate and Time . . . . . . . . . . . . . . . . 6

Pseudo Imbibition Capillary Pressure . . . . . . . . . . . . . . . . . . 7

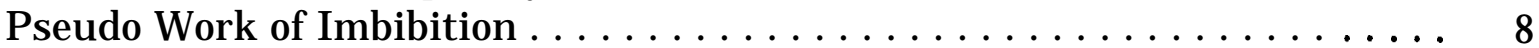

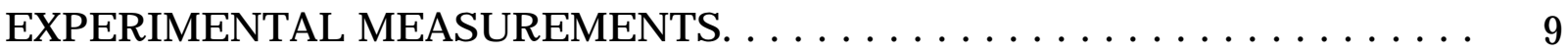

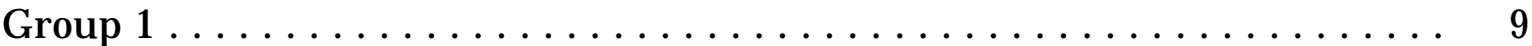

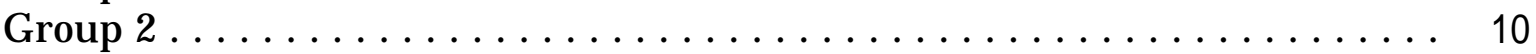

RESULTS AND DISCUSSION . . . . . . . . . . . . . . . . . 11

Determination of Constants $a$ and $b \ldots \ldots \ldots \ldots \ldots \ldots$

Comparison Between $\mathrm{W}_{\mathrm{R}}$ and $\mathrm{I}_{\mathrm{W}} \ldots \ldots \ldots \ldots \ldots \ldots \ldots \ldots$

Recovery Efficiency and Wettability ... . . . . . . . . . . . . . . . 14

CONCLUSIONS ............................... 20

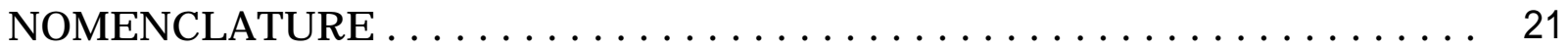

DISCLAIMER ............................. 22

REFERENCES ............................ 23 


\section{LIST OF TABLES AND FIGURES}

\section{Table}

Page

1 Properties of Liquid/Air/PTFE Systems $\ldots \ldots \ldots \ldots \ldots \ldots \ldots \ldots$

2 Crude Oil/Brine/Rock Systems with High $\mathrm{I}_{\mathrm{W}} \ldots \ldots \ldots \ldots \ldots$

Figure

Page

1 Effect of Contact Angle on Imbibition Capillary Pressures ......... 2

2 Examples of Effect of Contact Angle on Spontaneous Imbibition ..... 4

3 Imbibition Curves for Refined Oil/Brine/Rock and Crude Oil/Brine/Rock Systems that Both Have Very High Amott I ndices to Water $\left(2 \% \mathrm{CaCl}_{2}\right.$ Brine $) \ldots \ldots \ldots \ldots \ldots \ldots \ldots$

4 Effect of Aging Time on Oil Recovery by Spontaneous Imbibition vs. Time 12

5 Oil Recovery by Spontaneous Imbibition vs. Dimensional Time . . . . . 13

$6 \quad$ Pseudo Imbibition Capillary Pressure vs. Water Saturation . . . . . . . . 15

7 Relationship Between Relative Pseudo Work of Imbibition and Aging Time 16

8 Relative Pseudo Work of Imbibition Recovery, $R_{\text {im }}$, from Fig.4, and Waterflood Recovery, $R_{w f}$, vs. Aging Time, $t_{a}$, for Alaskan'93 Crude Oil 16

9 Maximum Imbibition Recovery, $R_{\text {im }}$, from Fig.4, and Waterflood Recovery, $R_{w f}$, vs. Aging Time, $t_{a}$, for Alaskan'93 Crude Oil . . . . . . 16

10 Relationships Between Waterflood Recovery and (a) Amott Wettability Index to Water and (b) Pseudo Relative Work of Imbibition . . . . . . . . 


\section{EXECUTIVE SUMMARY}

Of the many methods of characterizing nettability of a porous medium, the most commonly used are the Amott test and the USBM test. The Amott test does not discriminate adequately between systems that give high values of nettability index to water and are collectively described as very strongly water-wet. The USBM test does not recognize systems that achieve residual oil saturation by spontaneous imbibition. For such systems, and for any systems that exhibit significant spontaneous imbibition, measurements of imbibition rate provide a useful characterization of nettability.

Methods of interpreting spontaneous imbibition data are reviewed and a new method of quantifying wettability from rate of imbibition is proposed. Capillary pressure is the driving force in spontaneous imbibition. The area under an imbibition curve is closely related to the work of displacement that results from decrease in surface free energy. Imbibition rate data can be correlated to allow for differences in interracial tension, viscosities, pore structure, and sample size. Wettability, the remaining key factor in determining the capillary driving force and the related imbibition rate, then largely determines the differences in saturation vs. scaled time curves. These curves are used to obtain pseudo imbibition capillary pressure curves; a wettability index based on relative areas under these curves is defined as the relative pseudo work of imbibition. The method is applied for two crude oil/brine/rock systems. Comparison of the method with the Amott wettability index is made for different wettability states given by differences in aging of cores with crude oil. Correlations of wettability indices with waterflood recoveries are presented. 


\section{INTRODUCTION}

Reservoir wettability is recognized to be a critical issue in many types of oil recovery processes. Recovery of oil by spontaneous imbibition of water into the matrix blocks of fractured reservoirs is a frequently cited example. Many methods of characterizing nettability have been proposed. The Amott test ${ }^{1}$ and USBM test ${ }^{2}$ are the most commonly used methods of characterizing wettability of oil/brine/rock systems. Both depend on capillary pressure and microscopic displacement efficiency. In application of either test, it is common to first displace water by oil to reach an initial water saturation, $\mathbf{S}_{\mathrm{wi}}$. This step in the test is important because the wettability index, in addition to core treatment such as aging time and temperature, is strongly dependent on the value of the initial water saturation. ${ }^{3}$ The next step is to immerse the sample in water and measure the oil recovered by spontaneous imbibition. The corresponding increase in water saturation is $\mathbf{\Delta} \mathbf{S}_{\mathrm{ws}}$.

In the Amott test, the sample is then subjected to what is known as forced displacement either by centrifuging, as originally proposed by $A m o t t,{ }^{1}$ or by waterflooding. ${ }^{4}$ If the increase in water saturation by forced displacement is $\Delta \mathrm{S}_{\mathrm{wf}}$, the Amott nettability index to water, $\mathrm{I}_{\mathrm{w}}$, is then defined as

$$
I_{w}=\frac{\Delta S_{w s}}{\Delta S_{w s}+\Delta S_{w f}}
$$

If nearly all of the oil recovery occurs by spontaneous imbibition, $\mathrm{I}_{\mathrm{w}}$ is close to 1.0, and the system is described as very strongly water-wet. Systems are increasingly less water-wet as $I_{w}$ approaches 0 . Similarly, an Amott oil wettability index, $I_{0}$, can be defined by measuring spontaneous imbibition of oil, followed by forced displacement of water by oil. A continuous wettability scale from -1 to 1 , known as the AmottHarvey nettability index, $I_{A H}$, is given by the difference between $I_{w}$ and $I_{O}$.

In the USBM test, ${ }^{2}$ after spontaneous imbibition starting at $\mathbf{S}_{\mathrm{wi}}$ is complete, the sample is subjected to forced displacement of oil by centrifuging, with the speed increased by increments. A capillary pressure curve is derived from the centrifuge data, and the area under the forced imbibition curve, $\Sigma_{\text {wf }}$, is determined. The core sample is then submersed in oil. After spontaneous imbibition of oil is complete, the centrifuge method is used to measure the drainage curve for displacement of water by oil. The area under the drainage curve is designated $\Sigma_{\text {of }}$. The USBM wettability number is then defined by the logarithm of the ratio of the areas. 


$$
N_{U S B M}=\log \left(\frac{\Sigma_{o f}}{\Sigma_{w f}}\right)
$$

Both the USBM test and the Amott test have serious weakness with respect to discriminating between systems that fall within certain ranges of wettability. Relationships between drainage and imbibition displacement curvature and contact angle, obtained by correlation of experimental results for air/liquid displacements in a porous media of low surface energy, are shown in Figure 1 . This type of system is commonly described (relative to obvious cases of heterogeneous wetting such as mixedwettability $^{6}$ or fractional wettability ${ }^{7}$ ) as having uniform nettability. $\theta_{\mathrm{E}}$ corresponds to contact angles measured at smooth surfaces and $\theta_{\mathrm{A}}$ to advancing contact angles measured at roughened surfaces. Drainage curves in the contact angle, $\theta_{\mathrm{E}}$, range of $0^{\circ}$ to $55^{\circ}$ are not significantly affected by wettability, but there is a systematic decrease in imbibition capillary pressure with increase in contact angle. If trapping of the nonwetting phase is complete, $I_{w}$ will be unity, because forced displacement is not expected to reduce the trapped residual nonwetting phase, except at high capillary numbers. Thus the Amott index does not discriminate between systems that attain residual non-wetting phase without change in sign of imbibition capillary pressure. A comparable problem arises with the USBM test. For contact angles ranging from $\mathbf{0}^{\circ}$ to $5^{\circ}, \Sigma_{\mathrm{wf}}$ is zero. Thus, the USBM index does not recognize the existence of the type of variation in wetting behavior shown in Figure 1.

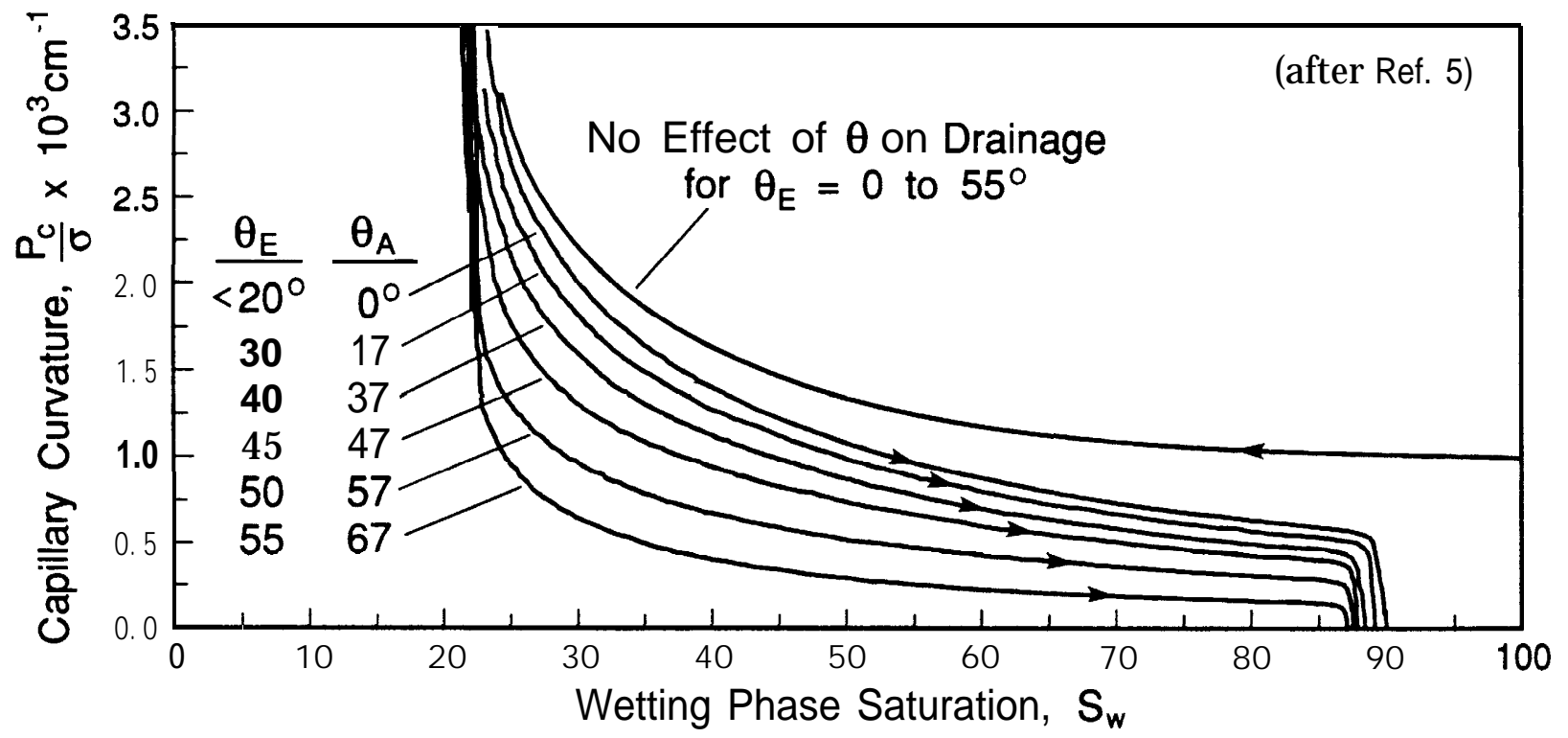

Figure 1. Effect of Contact Angle on Imbibition Capillary Pressures 
Measurement of imbibition capillary pressure curves provides a possible general approach to characterizing systems that have different degrees of water wetness, but they are difficult and tedious to make, especially for crude oil/brine/rock systems. Characterization of nettability by measurement of spontaneous imbibition rates ${ }^{8-11}$ is a more practical alternative and is the subject of the present work.

\section{Scaling of Spontaneous I mbibition}

The rate of increase of the wetting phase saturation is dependent on the interracial tension, $\sigma$, viscosities of the water and oil phases, $\mu_{w}$ and $\mu_{o}$, core geometry and exterior core surface boundary conditions, and the detailed pore structure and microscopic boundary conditions that determine nettability. An average microscopic pore radius can be defined that is proportional to the square root of permeability over porosity. ${ }^{12}$ Based on the work of Rapoport, ${ }^{13}$ Mattax and Kyte ${ }^{14}$ defined dimensionless time, $\mathrm{t}_{\mathrm{D}}$, as

$$
\mathrm{t}_{\mathrm{D}}=1.8849 \times 10^{-2} \mathrm{t} \sqrt{\frac{k}{\phi}} \frac{\sigma}{\mu_{w}} \frac{1}{L_{c}^{2}}
$$

where $t$ is in minutes, $k$ in $\mathrm{md}, \sigma$ in dynes/cm, $\mu_{w}$ in $\mathrm{cp}, L_{c}$ a characteristic length in $\mathrm{cm}$, and $\phi$ is the fractional porosity.

Correlation of results by Equation 3 to give a single recovery vs. $t_{D}$ curve is restricted to systems that have the same relative permeabilities, scalable capillary pressure curves, and wettability and viscosity ratio. Increase in contact angle decreases capillary imbibition pressure, and there is a corresponding decrease in rate of spontaneous imbibition. Examples of dependence on imbibition rate due mainly to differences in wetting ${ }^{5}$ are presented in Figure 2 and Table 1 for systems that can be expected, from the results shown in Figure 1 , to give an Amott index, $\mathrm{I}_{\mathrm{w}}$, of 1.0.

\section{Imbibition bv Crude Oil/Brine/Rock Svstems}

A further example of the ambiguity in wetting that can arise for systems with high Amott index to water is provided by the results for the crude oil/brine/rock systems ${ }^{15}$ shown in Figure 3. For this particular crude oil, designated ST-86, the value of $I_{w}$ for several brine compositions (see Table 2) was essentially the same as that obtained for recovery of refined oil under very strongly water-wet conditions. However, the spontaneous imbibition behavior (Figure 3) shows that the rate of recovery of crude oil was much slower than the rate of recovery for two refined oils, one of which had a viscosity comparable to that of the crude oil. 


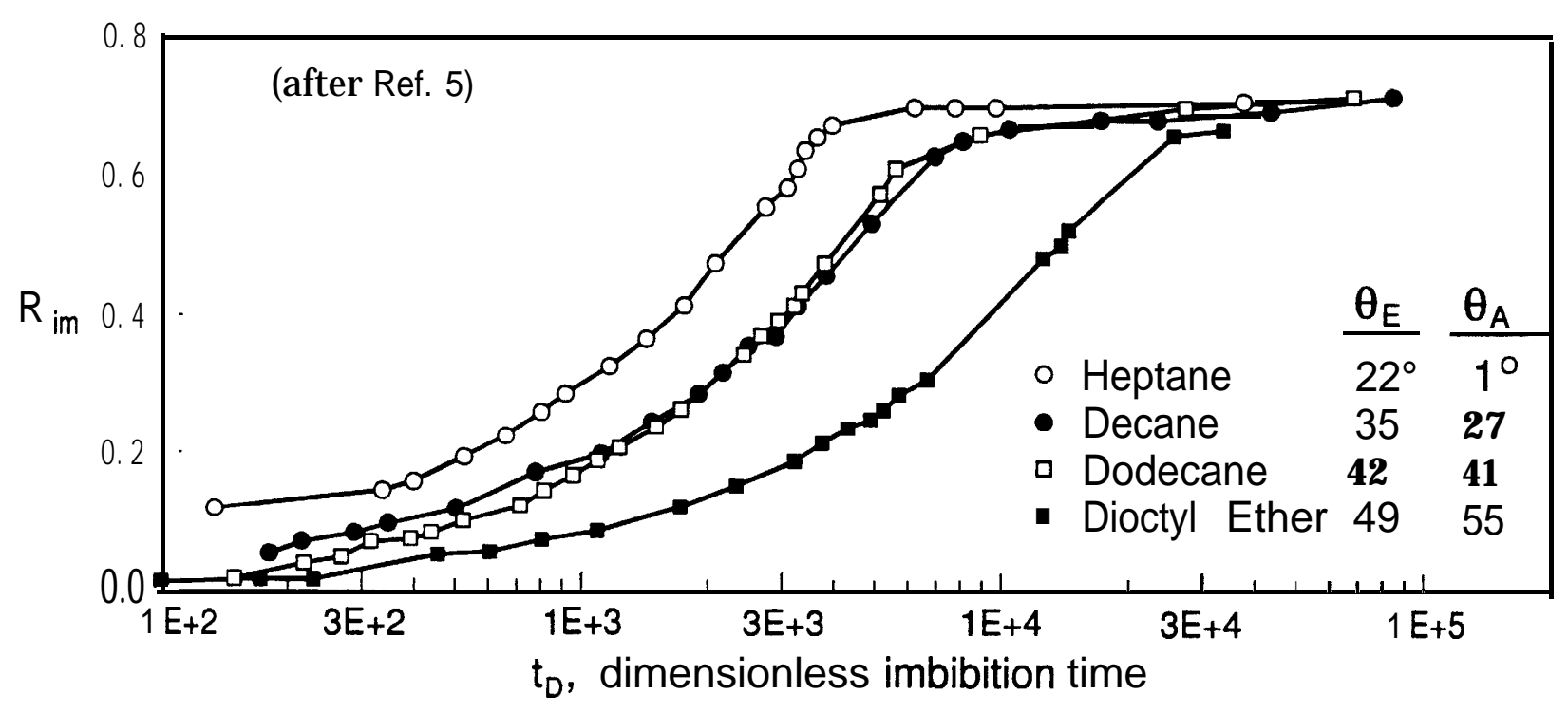

Figure 2. Examples of Effect of Contact Angle on Spontaneous Imbibition

Table 1. Properties of Liquid/Air/PTFE Systems

\begin{tabular}{||c|c|c|c|c||}
\hline \hline Liquid & $\mu\left(\mathrm{cp}, 23^{\circ} \mathrm{C}\right)$ & $\begin{array}{c}\sigma(\mathrm{dyn} . / \mathrm{cm}, \\
\left.26^{\circ} \mathrm{C}\right)\end{array}$ & $\theta_{\mathrm{E}}$ & $\theta_{\mathrm{A}}{ }^{*}$ \\
\hline Heptane & 0.404 & 18.9 & $22^{\circ}$ & $1^{\circ}$ \\
\hline Decane & $0.92^{\left(20^{\circ} \mathrm{C}\right)}$ & 23.4 & $35^{\circ}$ & $27^{\circ}$ \\
\hline Dodecane & 1.42 & 24.9 & $42^{\circ}$ & $41^{\circ}$ \\
\hline Dioctyl Ether & 3.52 & 27.3 & $49^{\circ}$ & $55^{\circ}$ \\
\hline \hline
\end{tabular}

*at roughened surfaces 


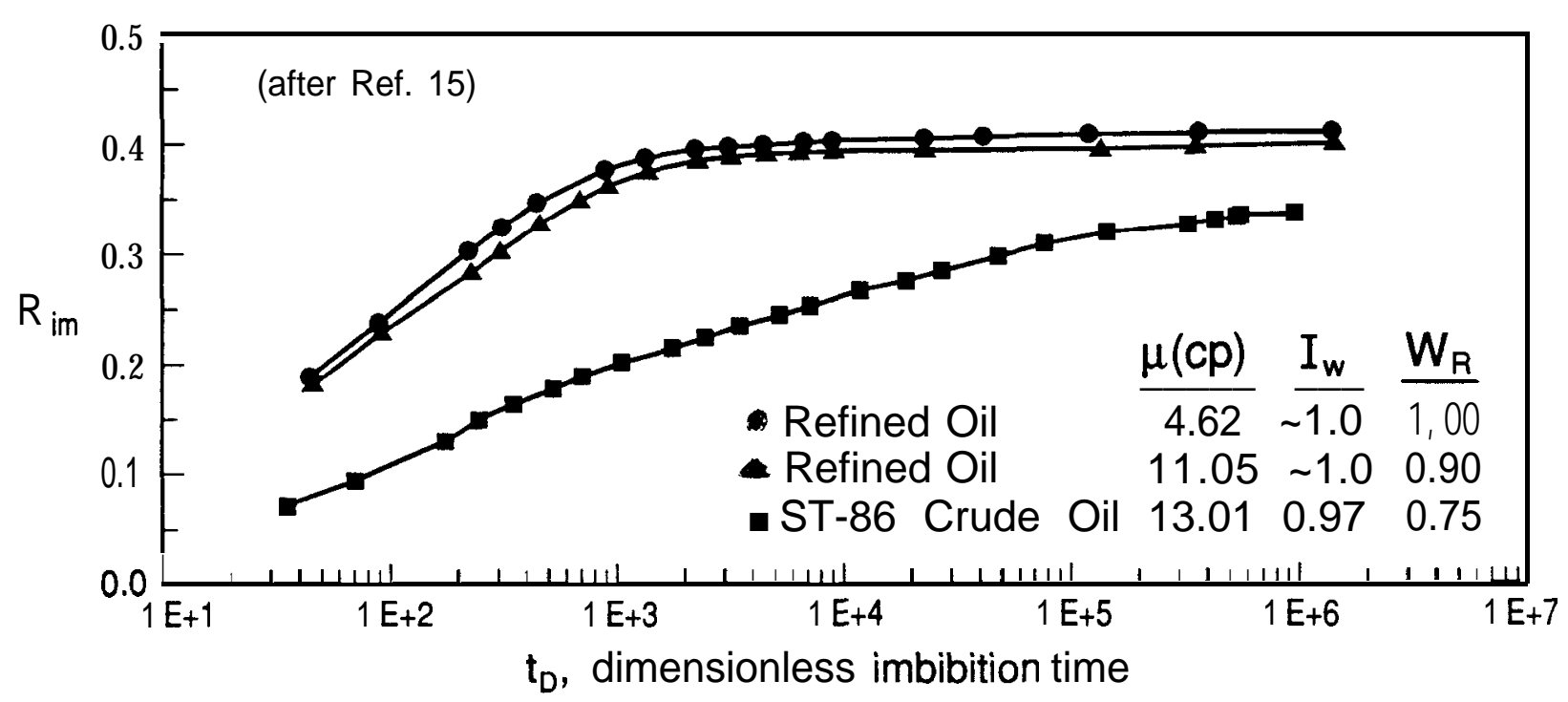

Figure 3. Imbibition Curves for Refined Oil/Brine/Rock and Crude Oil/Brine/Rock Systems that Both Have Very High Amott Indices to Water (2\% $\mathrm{CaCl}_{2}$ Brine)

Table 2. Crude Oil/Brine/R ock Systems with High $\mathbf{I}_{w}$ $\left(\mathrm{T}_{\mathrm{a}}=26^{\circ} \mathrm{C}, \mathrm{t}_{\mathrm{a}}=10\right.$ days, $\left.\mathrm{S}_{\mathrm{wi}}=25 \%\right)$

\begin{tabular}{|c|c|c|c|c|c|c|}
\hline \multicolumn{2}{|c|}{ Brine (\%) } & \multirow[b]{2}{*}{ Oil } & \multirow{2}{*}{$\begin{array}{c}\mu_{0} \\
(\mathrm{cp})\end{array}$} & \multirow{2}{*}{$\begin{array}{c}\sigma_{\mathrm{w}-\mathrm{O}} \\
(\mathrm{dyn} / \mathrm{cm})\end{array}$} & \multirow[b]{2}{*}{$\mathrm{I}_{\mathrm{w}}$} & \multirow[b]{2}{*}{$\mathrm{w}_{\mathrm{R}}$} \\
\hline $\begin{array}{c}\mathrm{NaC} \\
1 \\
\end{array}$ & $\begin{array}{c}\mathrm{CaCl} \\
2 \\
\end{array}$ & & & & & \\
\hline 0 & 2 & Refined oil & 4.62 & 29.33 & 1.0 & 1.0 \\
\hline 0 & 2 & Refined oil & 11.05 & 29.50 & 1.0 & 0.90 \\
\hline 0 & 2 & ST-86 & 13.01 & 24.60 & 0.97 & 0.75 \\
\hline 4 & 1 & ST-86 & 13.01 & 23.80 & 0.96 & 0.79 \\
\hline 6 & 1 & ST-86 & 13.01 & 24.59 & 0.96 & 0.79 \\
\hline 2 & 1 & ST-86 & 13.01 & 24.28 & 0.97 & 0.78 \\
\hline 4 & 0.5 & ST-86 & 13.01 & 23.78 & 0.94 & 0.78 \\
\hline
\end{tabular}


Reservoir core samples are generally believed to have mixed wettability, which is strongly related to the distribution of connate water within a core. ${ }^{6}$ Freshly recovered cores are commonly observed to expel oil by spontaneous imbibition when immersed in brine. Copious production of oil is regarded as evidence that the reservoir is very strongly water-wet with contact angles close to zero. However, wetting conditions under which crude oil/brine/rock systems exhibit spontaneous imbibition of water are not well understood. Systems that exhibit contact angles higher than $90^{\circ}$ to brine at smooth mineral surfaces are often capable of imbibing water, even if sometimes very slowly. These observations suggest that measurement of spontaneous imbibition rates of water for crude oil/brine/rock systems is a more widely applicable method of measuring wettability than is indicated by results for uniformly wetted systems. (From the results shown in Figure 1, spontaneous imbibition is limited to systems with equilibrium contact angles of less than about $62^{\circ}$ ).

Measurement of rates of spontaneous imbibition of oil also offer a method of quantifying the wettability of oil-wet systems, Obviously, neither imbibition rate method nor the Amott test can discriminate between systems that do not imbibe either oil or water in significant quantity. For such cases the USBM test is probably the best. The present work is focussed on characterization of systems that spontaneously imbibe water.

\section{THE ORY}

\section{Imbibition Rate and Time}

From the results of laboratory imbibition experiments reported by Mattax and Kyte, ${ }^{14}$ Bokserman et al. ${ }^{16}$ presented the following relationship between imbibition rate, $q(t)$, and imbibition time, t. ${ }^{17}$

$$
q(t)=\frac{c}{\sqrt{t}}
$$

The imbibition recovery, $\mathrm{R}_{\mathrm{im}}(\mathrm{t})$, can then be derived as

$$
R_{i m}(t)=\frac{1}{V_{P}\left(1-S_{w i}\right)} \int_{0}^{t} q(t) d t=\frac{2 c \sqrt{t}}{V_{P} S_{o 1}} \propto \sqrt{t}
$$


where $C$ is a constant, $S_{w i}$ and $S_{o i}$ are initial water and initial oil saturation respectively, and $\mathrm{V}_{\mathrm{p}}$ is pore volume.

The results reported by Mattax and Kyte ${ }^{14}$ were for open-surface sandstone cylinders and for alundum cylinders with only the bottom face open. For the alundum samples, the imbibition was therefore countercurrent and linear, The water viscosity was $0.9 \mathrm{cp}$ and the oil viscosity was $8.5 \mathrm{cp}$ for most of the tests. The viscosity ratio of about 9.4 was held constant when liquids of higher viscosity were tested (aqueous phase $12.9 \mathrm{cp}$ and oil phase $121 \mathrm{cp}$ ). Relationships similar to Equation 4 have been derived for capillary pressure-dominated countercurrent imbibition by combining Darcy's law and the material balance equation. $9,18,19$ Schechter and Zhou ${ }^{18}$ fitted the model with imbibition data measured for low permeability chalks reported by Cuiec, et al. ${ }^{20}$ Reis and $\mathrm{Cil}^{19}$ tested the model against the measurements reported by Mattax and Kyte. ${ }^{14}$ In all cases, a satisfactory fit was obtained between the model and the data.

Blair $^{21}$ simulated radial countercurrent imbibition by assuming that two ends of a cylindrical core sample (permeability of $200 \mathrm{md}$ and porosity of 32.1\%) were impermeable. The initial water saturation was $9.2 \%$, oil viscosity was $5 \mathrm{cp}$, and water viscosity was $1 \mathrm{cp}$. Blair found that the simulated imbibition recovery, $\mathrm{R}_{\mathrm{im}}$, was linearly proportional to imbibition time on a log-log scale with a slope of 0.38; thus the exponent oft was 0.62 rather than 0.5 in Equation 4.

Bourbiaux and Kalaydjian ${ }^{22}$ made imbibition measurements in which a refined oil, Soltrol 130, with a viscosity of $1.5 \mathrm{cp}$ was displaced by a barium chloride brine with a viscosity of $1.2 \mathrm{cp}$. The results showed that Equation 4 was valid for up to $80 \%$ oil recovery by concurrent imbibition except that the exponent oft was 0.45 rather than 0.5. For countercurrent imbibition, they found that the model held during the first hours of the test and also reported that Kisilenko and Ryzhik ${ }^{23}$ had obtained results which were fitted by Equation 4.

\section{Pscudo Imbibition Capillary Pressure}

Imbibition rate is proportional to imbibition capillary pressure, $P_{c}$, which is dependent on saturation. Examples of linear imbibition have been reported for which the main change in saturation occurs at a well-defined front. ${ }^{22,24}$ Thus $P_{c}$ and relative permeabilities to water and oil ahead of and behind the imbibition front are roughly 
constant. However, if a cylindrical core plug is immersed in wetting phase, as in common practice, the imbibition process will be far from linear. Water will invade the core by spontaneous imbibition from all directions. The manner in which the water saturation increases may range from frontal to global. Once an imbibition front reaches the center of the core sample, the imbibition capillary pressure will then decrease globally as the wetting phase saturation increases. Theoretical solutions for nonlinear imbibition are not available. Considering Darcy's law and the model expressed by Equation 4 for rate of imbibition, the following relationship defines a pseudo capillary pressure, $\mathrm{P}_{c, p s}\left(t_{D}\right)$

$$
P_{C, p s}\left(t_{D}\right)=\frac{a}{t_{D}^{b}}
$$

where $a$ and $b$ are constants. This pseudo capillary pressure, which is dimensionless, depends on the effect of nettability on both capillary pressure and the mobilities of the wetting and nonwetting phases. A plot of water saturation vs. $\mathrm{P}_{c, p s}\left(t_{D}\right)$ will be referred to as the $P_{c, p s}$ curve.

\section{Pseudo Work of Imbibition}

It can be shown that the area under an imbibition capillary pressure curve corresponds to work done by the system. This work is closely related to, but less than, the decrease in surface energy of the system. ${ }^{25}$ The change in surface free energy thatt accompanies spontaneous imbibition would provide a useful global measure of nettability, but there is no convenient method of measurement. An alternative measure of wettability, the area under the $P_{c, p s}$ curve, $W$, can be obtained directly from measurements of spontaneous imbibition. Although $W$ is based on a pseudo pressure and does not have a thermodynamic basis, by analogy with the area under a capillary pressure vs. displacement curve, the quantity $\mathrm{W}$ will be referred to as pseudo work of imbibition

$$
W=\int_{S_{w i}}^{1-S_{o r, i m}} P_{c, p s} d S_{w}=a \int_{S_{w i}}^{1-S_{o r, i m}} \frac{d S_{w}}{t_{D}^{b}}
$$

where $S_{o r, i m}$ is the residual oil saturation remaining in the core after the capillary pressure falls to zero and imbibition ceases. Because $P_{c, p s}$ is dimensionless (Equation 6), $\mathrm{W}$ is dimensionless. 
Strongly water-wet systems will usually have the maximum value of $\mathrm{W}, W_{s w w}$, and $W_{s w w}$ can be used to normalize results for other systems. If $W_{s w w}$ is taken as the normalization base, then the relative pseudo work of imbibition is defined as,

$$
W_{R}=\frac{W}{W_{s w W}}=\frac{\int_{S_{v i}}^{1-s_{o x, i-i v}} \frac{d S_{w}}{t_{B}^{b}}}{\left(\int_{S_{v i}}^{1-S_{o r, i n}} \frac{d S_{w}}{t_{D}^{b}}\right)_{s w w}}
$$

The index of wettability provided by $W_{R}$ for systems that exhibit spontaneous imbibition of water will usually range from 0 to 1 . Use of $\mathrm{W}_{\mathrm{R}}$ to discriminate between strongly wetted systems is illustrated by the values included in Table 2 and Figure 3. An analogous form of wettability index can also be defined for systems that imbibe oil. The index reflects both amount and rate of oil production with emphasis on early time recovery.

\section{EXPERIMENTAL MEASUREMENTS}

Twenty-one Berea core plugs were cut with diameters of about $3.8 \mathrm{~cm}$ and lengths in the range $6.2-7.2 \mathrm{~cm}$. A refined mineral oil, Soltrol 220 (density $0.7877 \mathrm{~g} / \mathrm{cc}$ and viscosity $3.35 \mathrm{cp}$ ), was used to obtain results for a strongly water-wet system. The cores were in two groups. Group 1 consisted of thirteen samples for which spontaneous imbibition curves, Amott wettability indices to water, and waterflood recovery curves were obtained. Group 2 consisted of eight samples for which spontaneous imbibition measurements were made.

\section{Group 1}

Porosities of the core samples in Group 1 were about $22 \%$ and absolute brine permeabilities were in the range of $300-350 \mathrm{md}$. A dead anaerobic crude oil, designated Alaskan'93 was used as the oil phase. Light ends were removed from the crude oil by evacuation for about two hours in order to minimize the possible formation of gas bubbles during the course of an experiment. The crude oil so treated had a density of $0.895 \mathrm{~g} / \mathrm{cc}$ and a viscosity of $39.25 \mathrm{cp}$ at $25^{\circ} \mathrm{C}$. A synthetic formation brine with density of $1.012 \mathrm{~g} / \mathrm{cc}$ and viscosity of $0.967 \mathrm{cp}$ was prepared. The brine 
composition was $21.3 \mathrm{~g} / \mathrm{l} \mathrm{NaCl}, 0.6 \mathrm{~g} / 1 \mathrm{CaCl}_{2} \cdot 6 \mathrm{H}_{2} \mathrm{O}, 0.1 \mathrm{~g} / \mathrm{K} \mathrm{KCl}$, and $0.2 \mathrm{~g} / 1$ $\mathrm{MgCl}_{2} \cdot 6 \mathrm{H}_{2} \mathrm{O}$. The interracial tension between the brine and the crude oil was 24 . 2 dynes/cm measured by du Nouy ring tensiometer. The interracial tension between Soltrol 220 mineral oil and the brine was 30 dynes/cm.

Core samples were first saturated with brine and allowed to equilibrate for 10 days. The brine was then displaced by 3 to 5 PV of oil at 25 to 30 psi pressure drop, as required to give initial water saturations close to $25 \%$. The direction of oil flow was reversed to alleviate end effects. Next, the core samples were aged at reservoir temperature $\left(88^{\circ} \mathrm{C}\right)$ for times ranging from one to 240 hours. After aging, the core was flushed with fresh crude oil before measuring rates of spontaneous imbibition. Oil recovery by imbibition was determined from the change in weight of the core suspended under water. Expelled oil that remained attached to the core sample was removed with the aid of a PTFE (Teflon) rod prior to recording the core weight. The imbibition test was run for at least four days, after which time oil production had essentially ceased for most of the samples. The samples were then waterflooded to determine the fraction of oil recovered by forced displacement. Finally, the samples were restored to $\mathbf{S}_{\text {wi }}$ by oil flooding and then waterflooded at 5 psi injection pressure (flow rates were about $0.2 \mathrm{cc} / \mathrm{s}$ ). Oil recovery vs. pore volumes of water injected was recorded.

\section{Group 2}

The eight samples that comprised Group 2 were saturated with $2 \% \mathrm{CaCl}_{2}$ brine. Pore volume and porosity were determined gravimetrically. Core permeabilities to brine were all close to $500 \mathrm{md}$. The density of the brine was $1.01 \mathrm{~g} / \mathrm{cc}$ and the viscosity was $0.9964 \mathrm{cp}$. Lagrave crude oil (density of $0.835 \mathrm{~g} / \mathrm{cc}$ and viscosity of $7.35 \mathrm{cp}$ ) was used to induce core nettability change. The interracial tension between the brine and crude oil was 23.1 dynes/cm. Initial water saturation, typically about $25 \%$, was obtained by gas/water drainage of the sample on a porous plate. The core was then filled with crude oil and the initial water saturation was remeasured gravimetrically. The sample was then aged under crude oil at $80^{\circ} \mathrm{C}$ for periods ranging from six hours to six weeks. After aging, the sample was removed from the oven and allowed to cool. Measurements of oil recovery by imbibition vs. time were made as described for Group 1 cores. 


\section{RESULTS AND DISCUSSION}

Relationships between oil recovery and time for Alaskan'93 and Lagrave crude oil are shown in Figures $4 a$ and $4 b$ respectively. There is a consistent decrease in imbibition rate with increase in aging time for both sets of data. Thus, variation of aging time provides a method of changing nettability systematically while keeping other rock and fluid properties constant (conditions at which imbibition curves are independent of further aging were not identified for either oil). Plots of recovery by imbibition vs. dimensionless time, $t_{\mathrm{D}}$, defined by Equation 5 , are presented in Figures $5 \mathrm{a}$ and $5 \mathrm{~b}$ for the two oils respectively. The main difference between Figure 4 and Figure 5 is that the effect of $\sigma$ on the imbibition rates was compensated. The crude oil viscosity was an order of magnitude higher than that of the Soltrol 220. The effect of viscosity of refined oils on spontaneous imbibition is indicated by the results shown in Figure 3. It seems likely that the correlation of imbibition data could be improved to give an acceptable universal base curve for strongly water-wet conditions. This would be particularly useful for application of the method to cores that are difficult to clean.

\section{Determination of Constants $\mathbf{a}$ and $\mathbf{b}$}

To determine a relationship between pseudo imbibition capillary pressure and imbibition time from Equation 6 , the constants $a$ and $b$ must be determined. In the earlier discussion of relationships between imbibition rate and time, various estimates of b were obtained: 0.45 by Bourbiaux and Kalaydjian ${ }^{22}$ determined by experiment; 0.5 from theory by Gatenby and Marsden ${ }^{9}$, Schechter and Zhou ${ }^{18}$ and Reis and $\mathrm{Cil}^{19}$; and 0.62 by Blair $^{21}$ determined from simulation. The value of $b=0.5$, which falls about midway in the range of previous estimates, gave the best correlation between $\mathrm{W}_{\mathrm{R}}$ and aging time. 


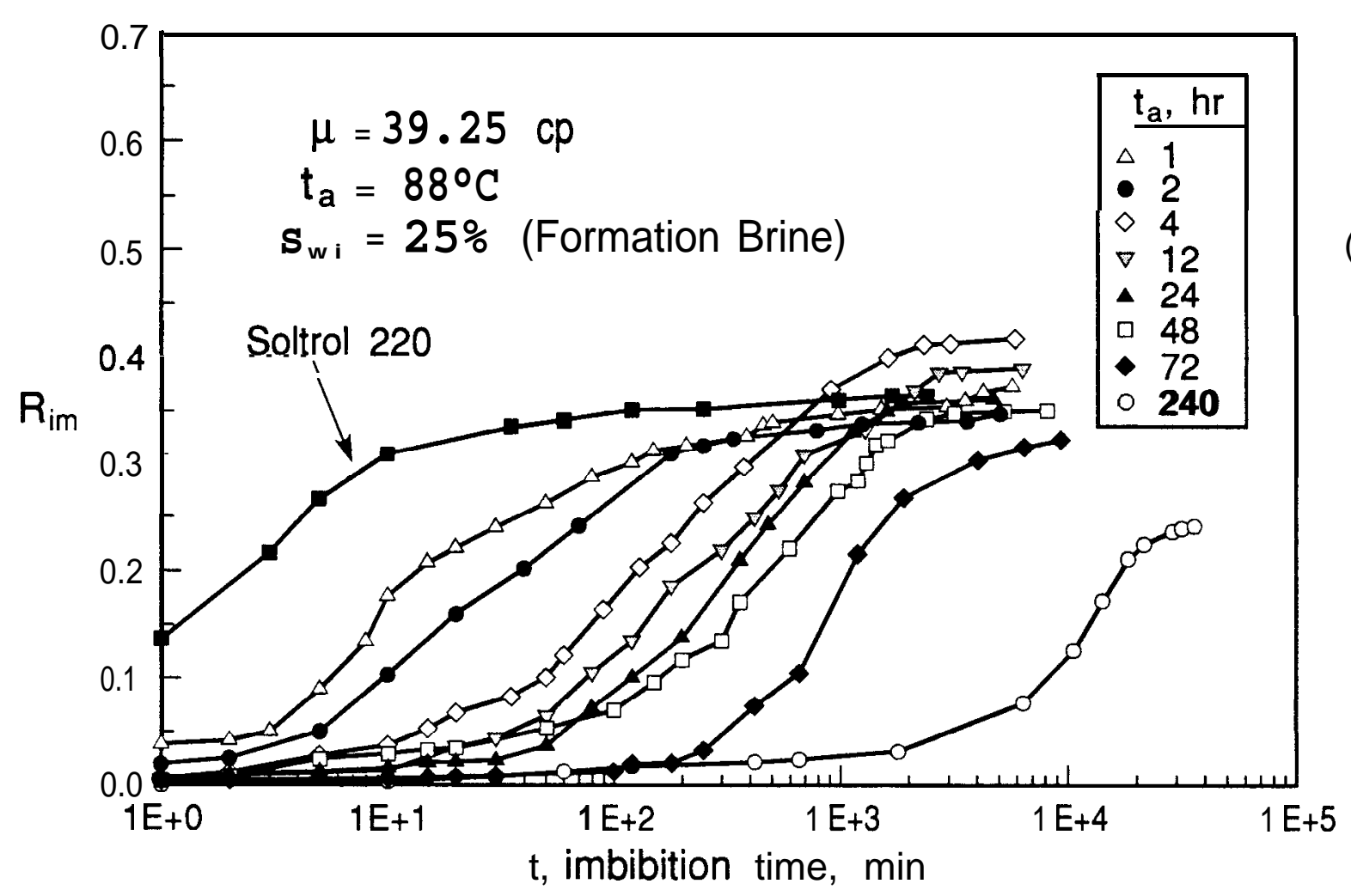

(a)

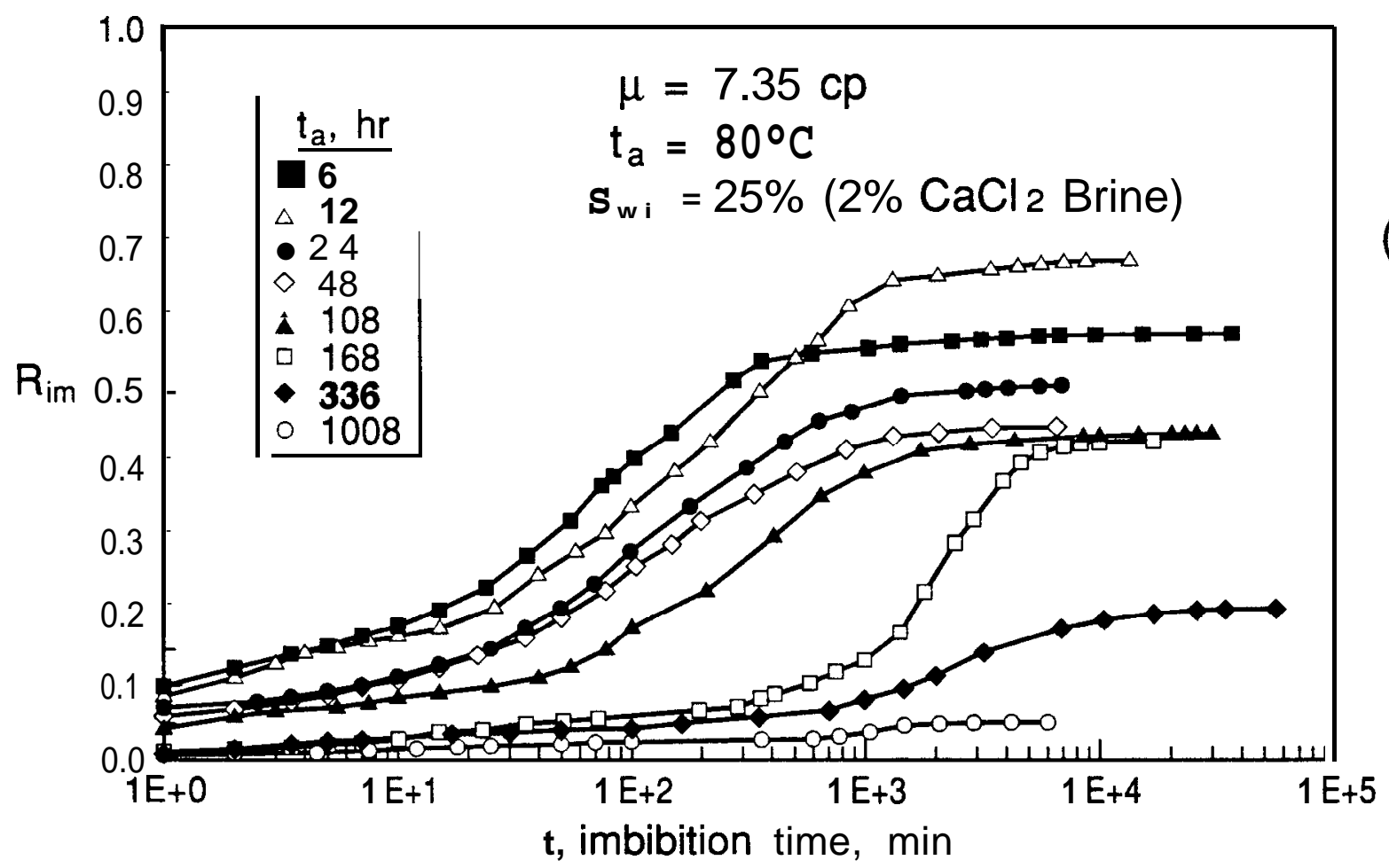

(b)

Figure 4. Effect of Aging Time on Oil Recovery by Spontaneous Imbibition vs. Time for (a) Alaskan'93 Crude Oil, $\mu=39.25 \mathrm{cp}$ and (b) Lagrave Crude Oil, $\mu=7.35 \mathrm{cp}$ 


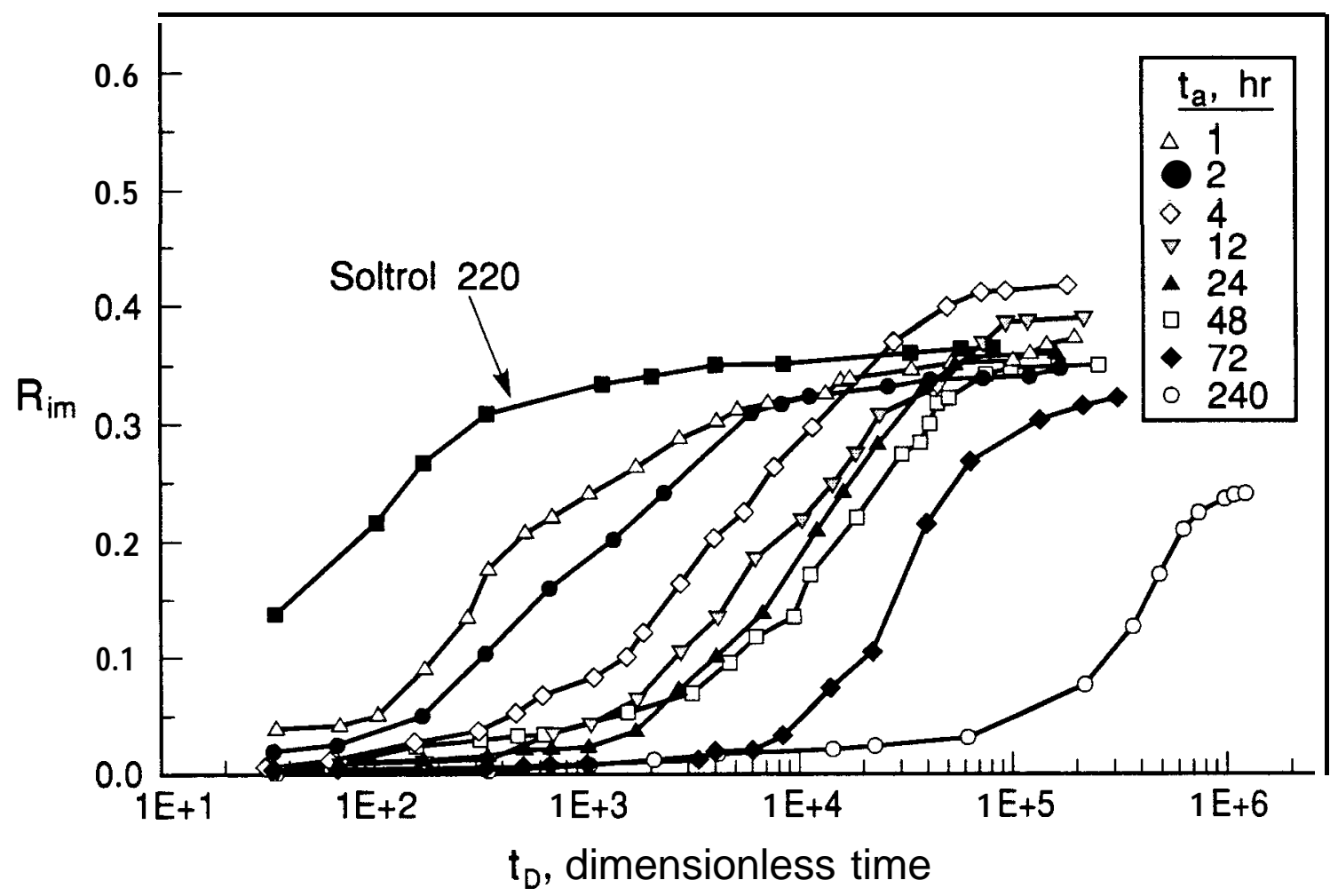

(a)

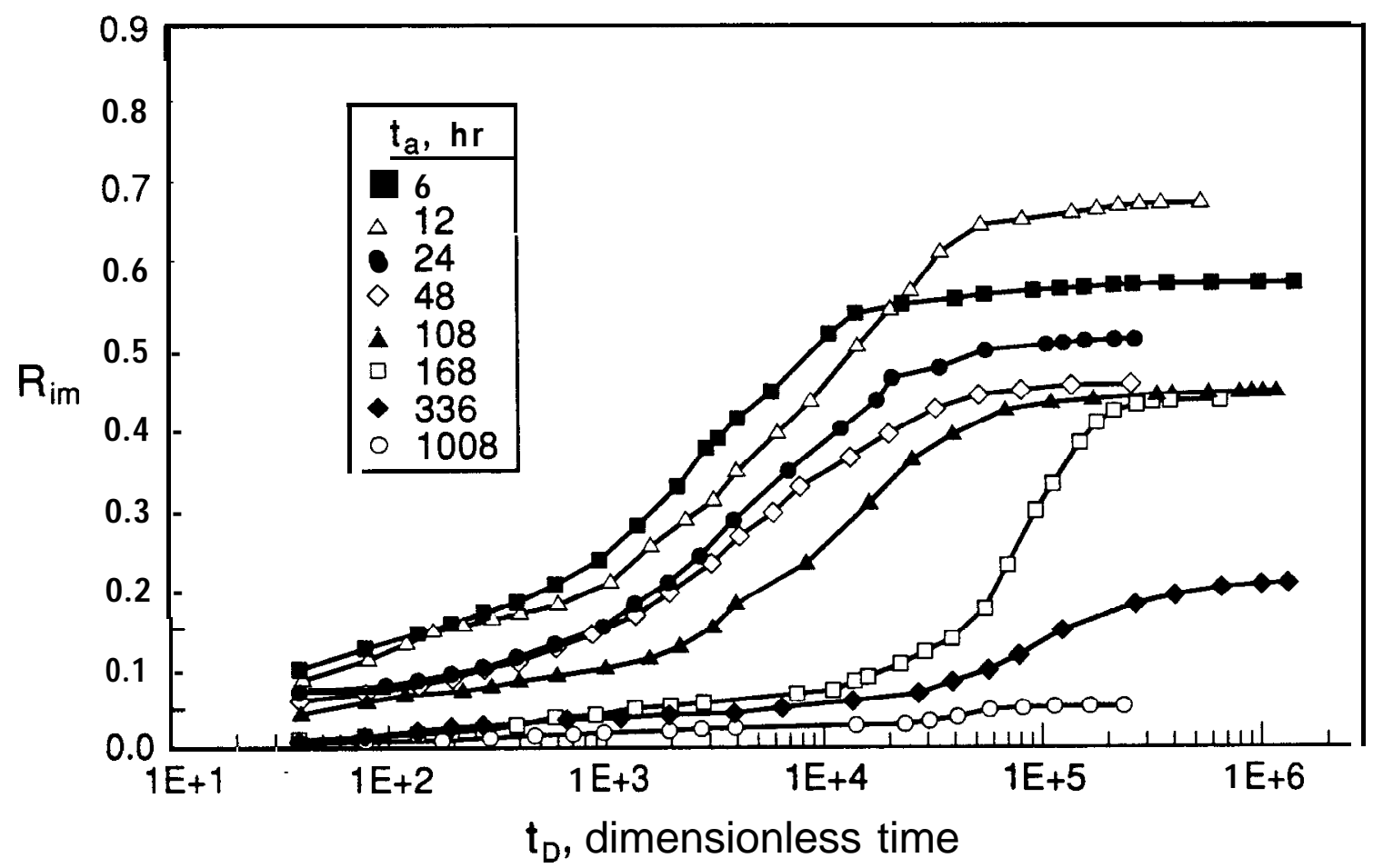

(b)

Figure 5. Oil Recovery by Spontaneous Imbibition vs. Dimensionless Time for (a) Alaskan'93 Crude Oil and (b) Lagrave Crude Oil 
- Since $P_{c, p s}$ is proportional to the $\operatorname{constant~} a$ (Equation 6), the relative work, $\mathrm{W}_{\mathrm{R}}$, is independent'of a (Equation 8). In determining the pseudo capillary pressure curves shown in Figures $6 \mathrm{a}$ and $6 \mathrm{~b}$ by application of Equation 6, a value of 1 was assigned to the constant, $a$.

Curves shown in Figures $6 a$ and $6 \mathrm{~b}$ were integrated, and the areas were normalized with respect to the results for a strongly water-wet system. The normalized work of imbibition was plotted against aging time for the two data sets given by the Alaskan'93 and Lagrave crude oils (see Figure 7). For both oils, the relative pseudo work of imbibition, $\mathrm{W}_{\mathrm{R}}$, decreases approximately logarithmically as aging time increases. For each oil, there was a well defined trend apart from one data point in each data set. In each case, departure from the overall trend appears to be caused mainly by the sensitivity of relative pseudo work, $\mathrm{W}_{\mathrm{R}}$, to early time recovery behavior.

\section{Comparisen Between $\mathrm{W}_{\mathbf{R}}$ and $\mathrm{I}_{\mathbf{w}}$}

Figure 8 shows the two measures of nettability, relative pseudo work of imbibition, $W_{R}$, and Amott nettability index to water, $\mathrm{I}_{\mathrm{w}}$, plotted against aging time for Alaskan'93 crude oil. All the systems with aging times of 12 hours or less gave Amott nettability indices to water higher than 0.8. Systems with Amott indices in this range are usually classed as very strongly water-wet. In contrast, the relative pseudo work of imbibition, $W_{R}$, for systems aged for $\mathbf{1 2}$ hours or less, ranged from about 0.35 to 0.9 because of the differences in imbibition rate that arise because of nettability differences. Thus, in differentiating between nettability states in this range of water wetness, the use of $\mathrm{W}_{\mathrm{R}}$ has a distinct advantage.

\section{Recovery Efficiencv and Wettability}

The relationship between recovery of Alaskan'93 crude oil by spontaneous imbibition and aging time is shown in Figure 9. Imbibition recovery first increases with aging time but then decreases. (The low recovery shown for two hours' aging time does not fit the overall trend, possibly because insufficient time was allowed for imbibition. ) The maximum in imbibition recovery is at $W_{R} \approx 0.5$ (from Figures 8 and 9). Waterflood recoveries, $R_{w f}$, are also included in Figure 9 and are shown to increase with aging time. 


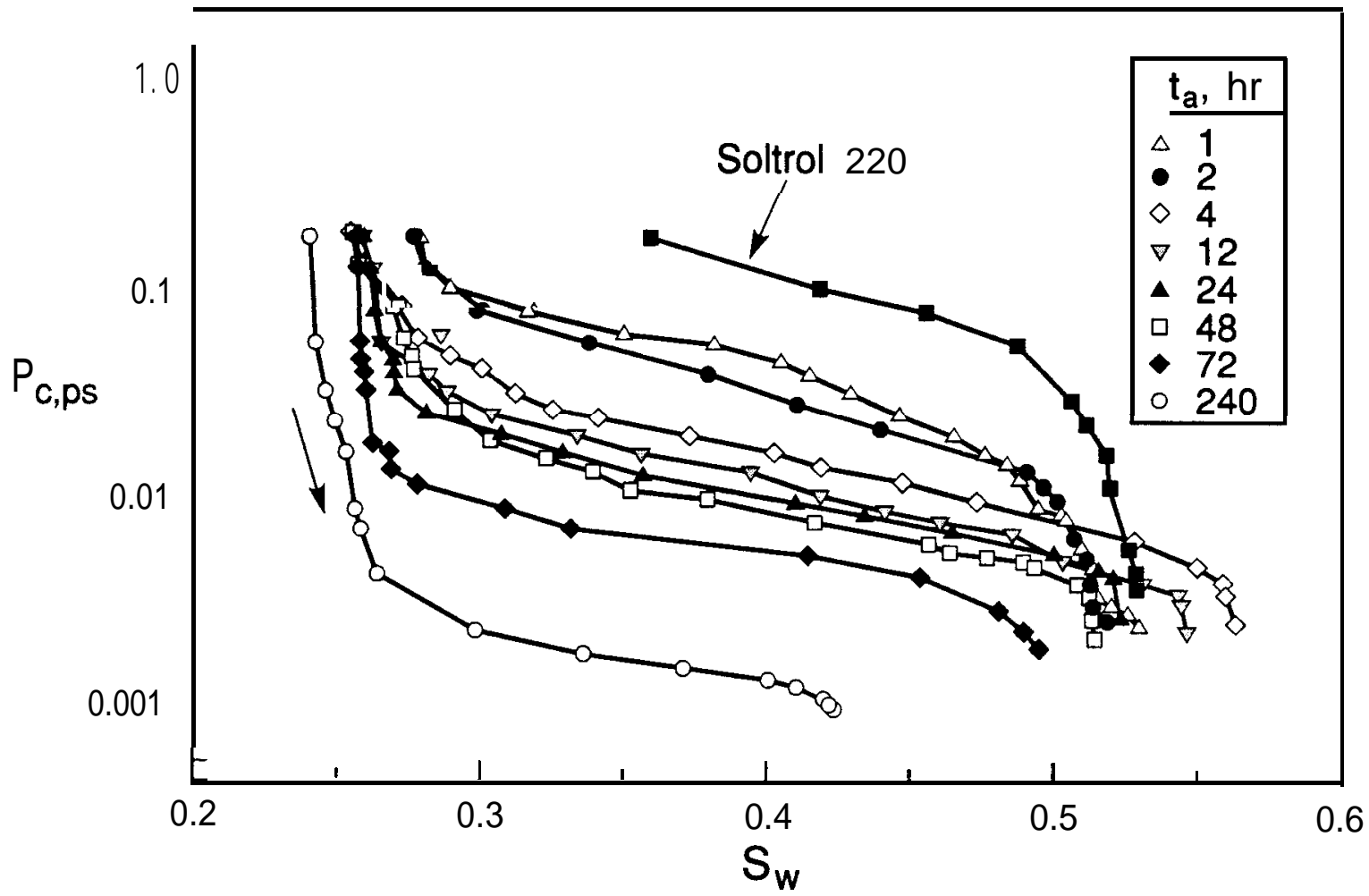

(a)

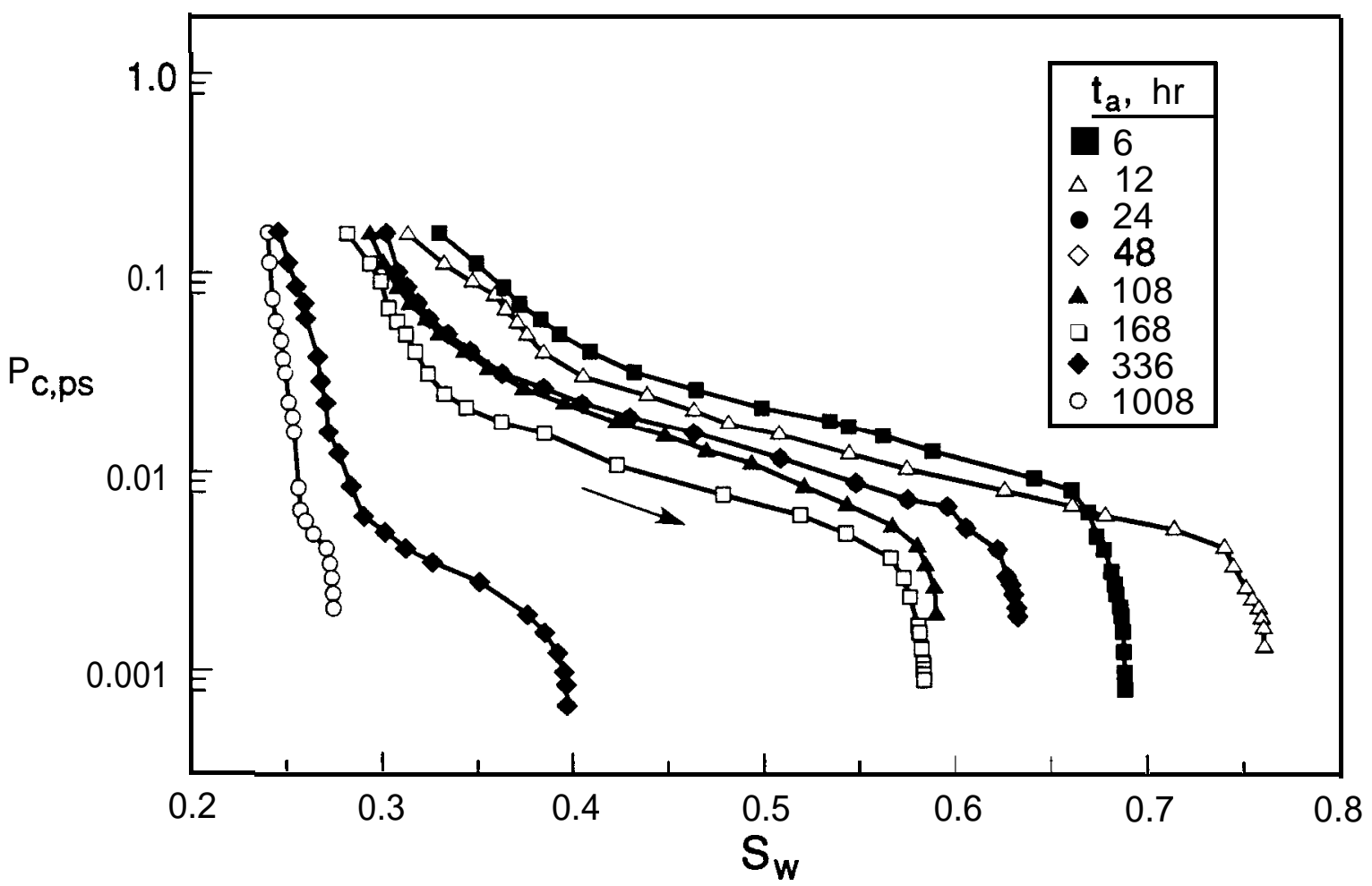

(b)

Figure 6. Pseudo Imbibition Capillary Pressure vs. Water Saturation for (a) Alaskan'93 Crude Oil and (b) Lagrave Crude Oil 


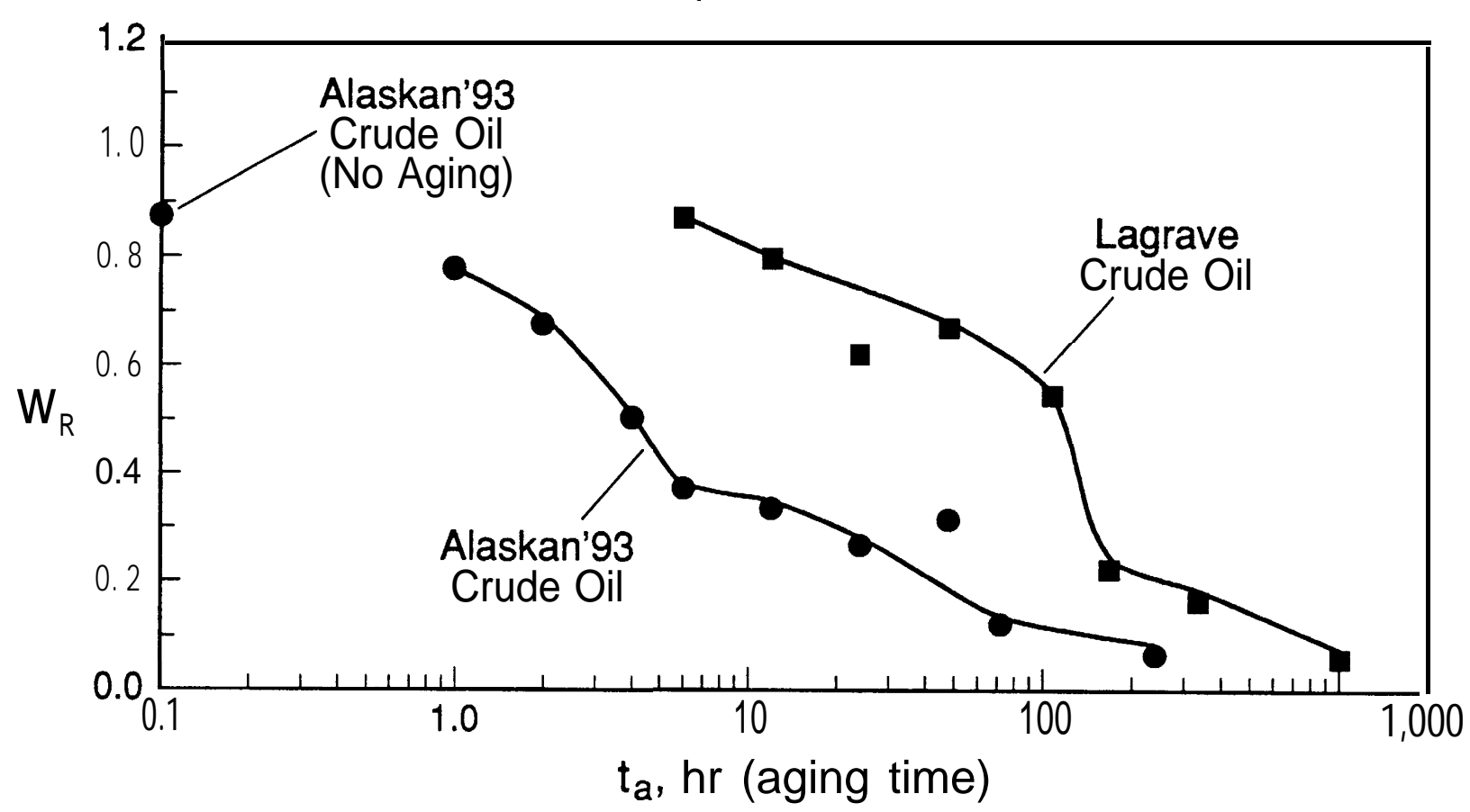

Figure 7. Relationship Between Relative Pseudo Work of Imbibition and Aging Time

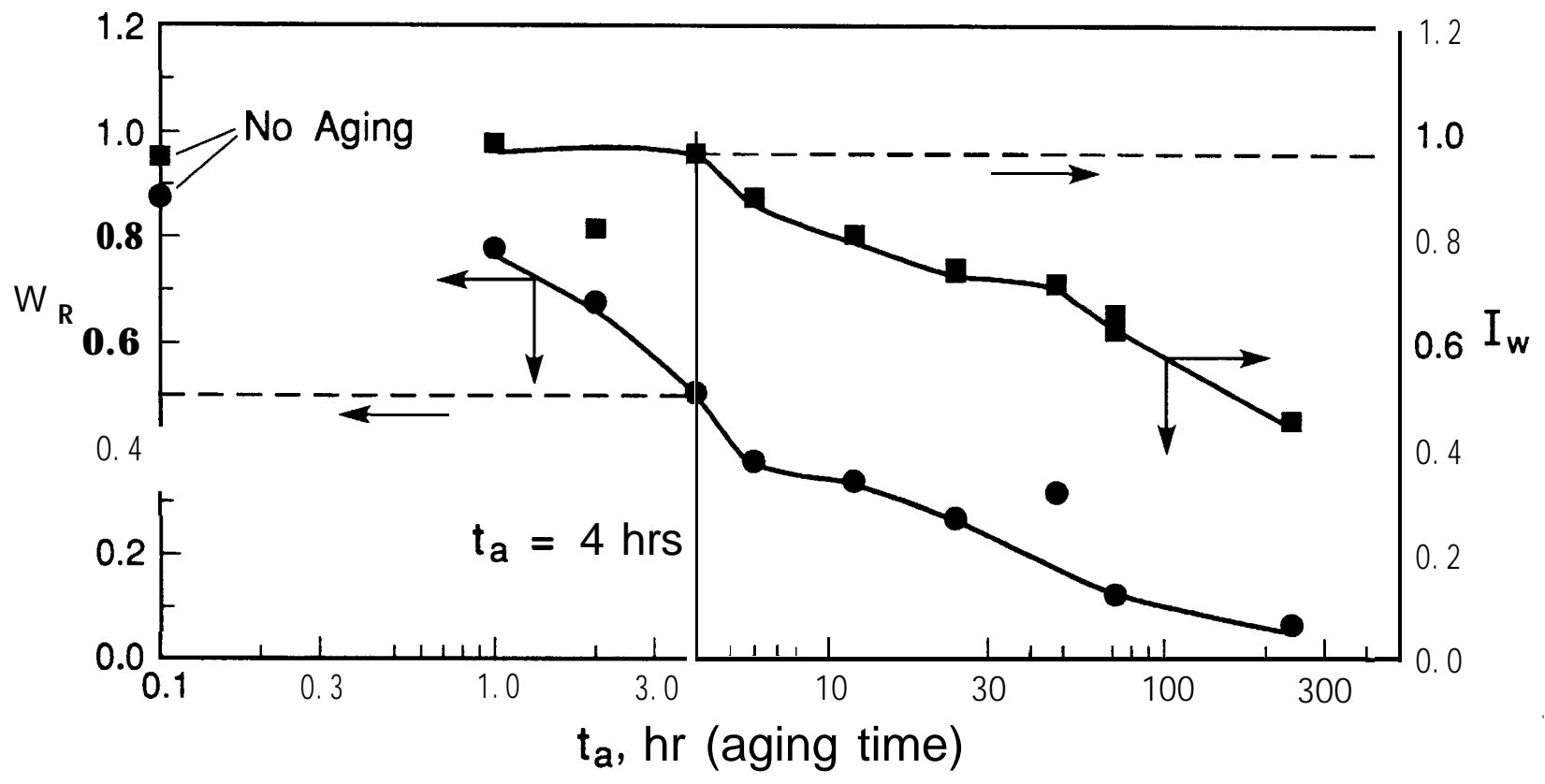

Figure. 8 Relative Pseudo Work of Imbibition Recovery, $R_{\text {im }}$, from Fig. 4 and Waterflood Recovery, $R_{w f}$ vs. Aging Time, $t_{a}$, for Alaskan'93 Crude Oil 


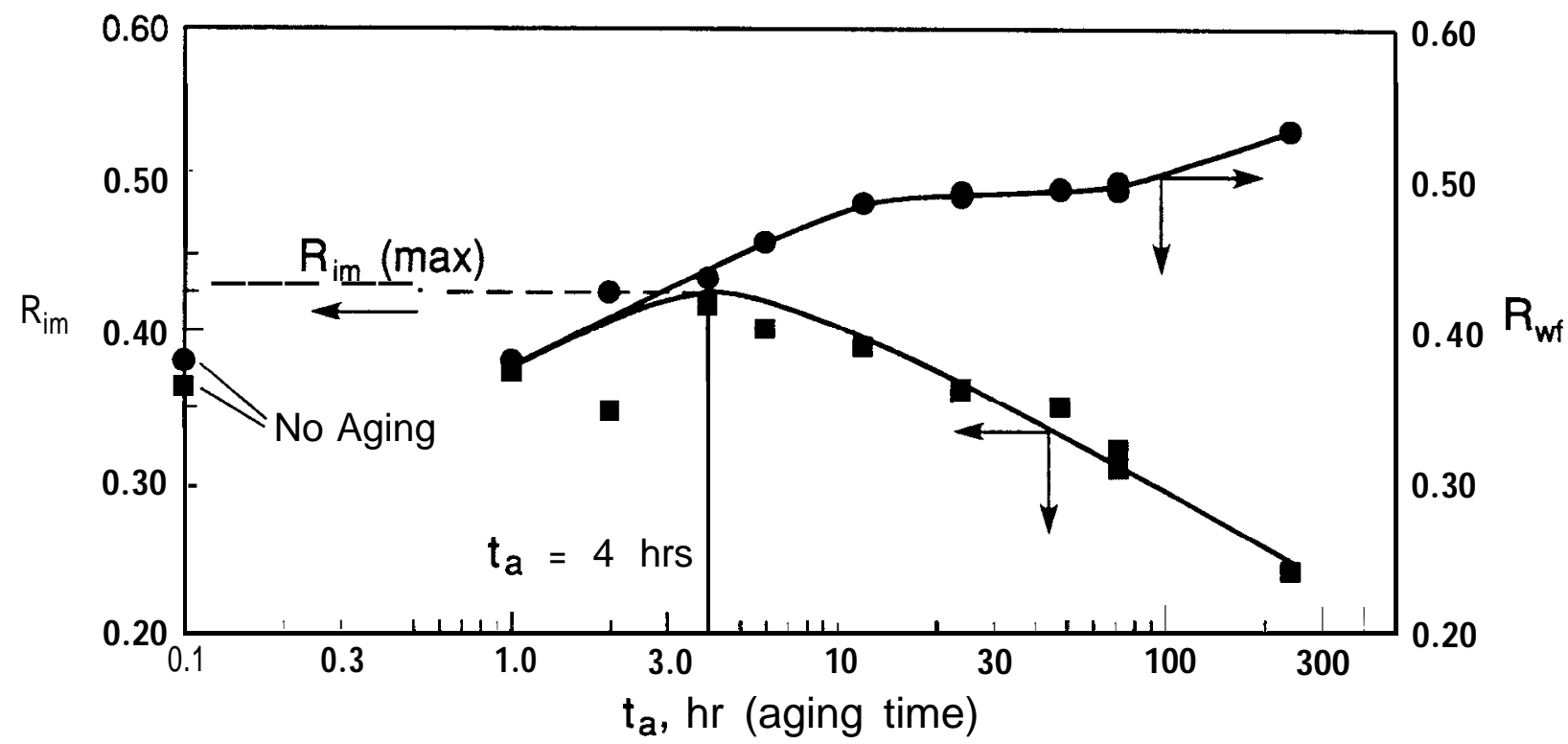

Figure 9. Maximum Imbibition Recovery, $R_{\text {im }}$, from Fig. 4 and Waterflood Recovery, $R_{w f}$ vs. Aging Time, $t_{a}$, for Alaskan'93 Crude Oil

For one, four, six, and 12 hours' aging, oil recovery by spontaneous imbibition is about equal to or exceeds the waterflood recovery obtained for strongly water-wet conditions. These results indicate that microscopic displacement efficiency increases as the system becomes less water-wet. Microscopic displacement efficiency for both spontaneous imbibition and waterflooding is governed by complex capillary phenomena related to stability of capillary structures and motion of three phase (oil/brine/solid) lines of contact. In very strongly water-wet systems, trapping of oil is dominated by snap-off. The results shown in Figure 9 imply that snap-off is inhibited as the systems become less strongly water-wet. Observations on the effect of contact angle on snap-off in model pores ${ }^{26}$ are consistent with this conclusion.

Oil recovery by spontaneous imbibition depends on the combined effect of wettability on microscopic displacement efficiency and capillary pressure. The maximum recovery by spontaneous imbibition, given by four hours' aging time (see Figure 9), is only slightly less than the corresponding recovery obtained by waterflooding. Above four hours' aging time, the waterflood and imbibition recoveries diverge markedly.

The decrease in oil recovery by imbibition for aging times above four hours is mainly governed by the water saturation at which the imbibition capillary pressure falls to zero. As aging time is increased, cessation of imbibition occurs at increasingly 
lower water saturations. Although imbibition recoveries decrease with aging time, waterflood recoveries show a remarkable increase (Figure 9). This implies that microscopic displacement efficiency increases as the system becomes less water-wet.

The relationship between waterflood recovery and spontaneous imbibition behavior is largely consistent with results reported previously by Morrow et al., ${ }^{27}$ J adhunandan and Morrow, ${ }^{3}$ and Villard et al. ${ }^{28}$ for other crude oils. Maximum waterflood recoveries were obtained at close to very weak water-wet conditions. ${ }^{3}$

Waterflood recovery, $\mathrm{R}_{\mathrm{wf}}$, is plotted against Amott nettability index to water, $\mathrm{I}_{\mathrm{w}}$, in Figure 10a and against relative pseudo work of imbibition, $W_{R}$, in Figure10b. For systems with high $\mathrm{I}_{\mathrm{w}}$, relative pseudo work of imbibition gives a distinctly better correlation with waterflood recovery than Amott wettability index to water. From Figure 10b, it can be seen that waterflood recoveries increase systematically with decrease in relative pseudo work of imbibition, a measure of wettability that is strongly related to the rate of spontaneous imbibition.

\section{CONCLUSIONS}

Results of the present study support the following conclusions.

1. Relative pseudo work of spontaneous imbibition can be used to characterize wettability in a way that reflects both rate and amount of oil production with emphasis on early time recovery. The method is especially useful for discrimination between systems that exhibit high Amott indices.

2. Increases in aging time provided systematic change in wettability, with other core and fluid properties held essentially constant. Correlation between relative pseudo work of imbibition, $\mathrm{W}_{\mathrm{R}}$, and aging time showed separate trends for the two crude oil/brine/rock systems that were investigated. Relationships between aging time and $\mathrm{W}_{\mathrm{R}}$ were approximately logarithmic.

3. Oil recovery by spontaneous imbibition was maximum at $\mathrm{W}_{\mathrm{R}} \approx 0.5\left(\mathrm{I}_{\mathrm{W}}>0.8\right)$.

4. Direct comparison of waterflood recoveries with imbibition rates (quantified as pseudo work of spontaneous imbibition) shows that oil recovery by waterflooding increases as the rate of water imbibition decreases. 


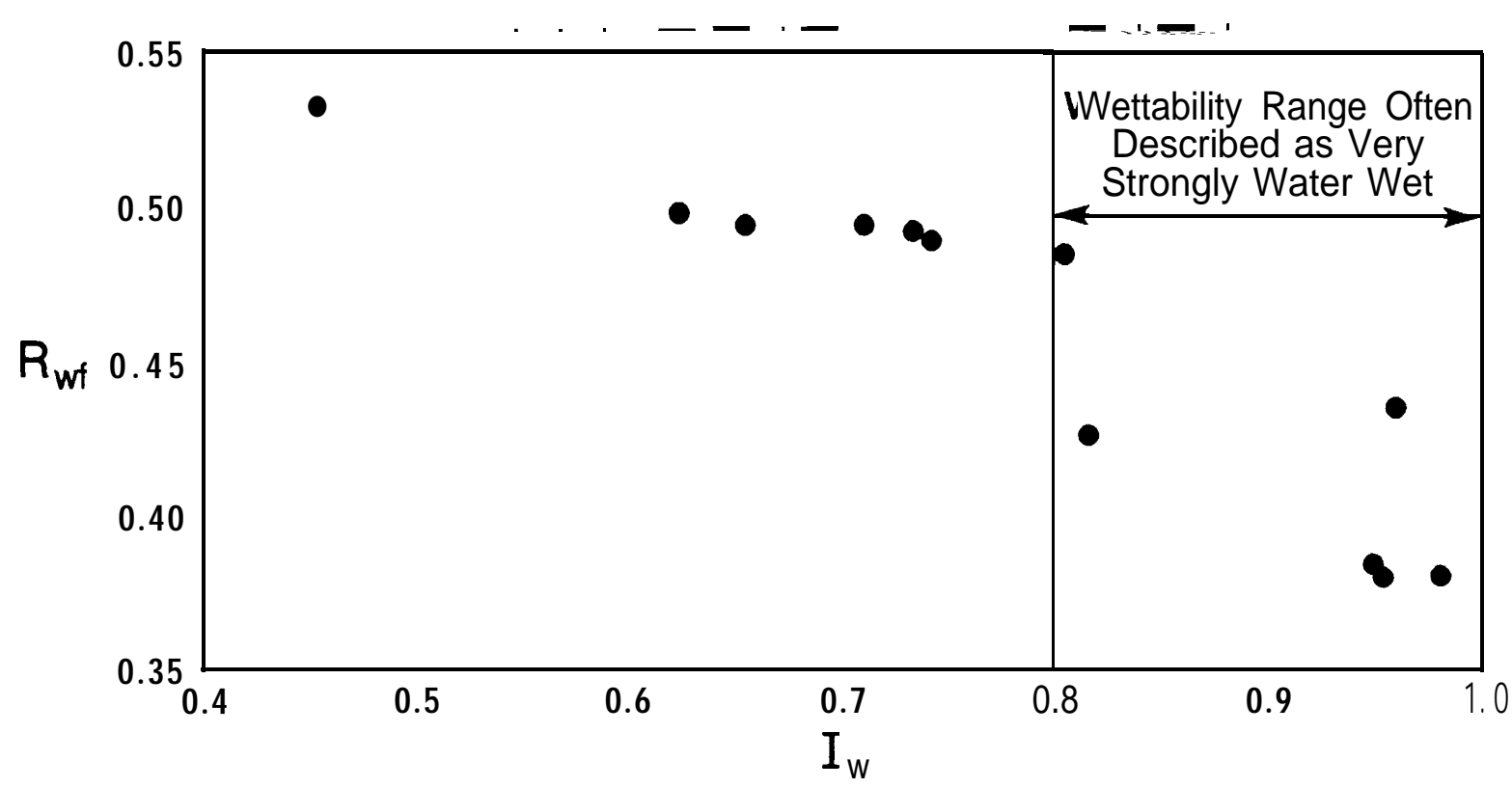

(a)

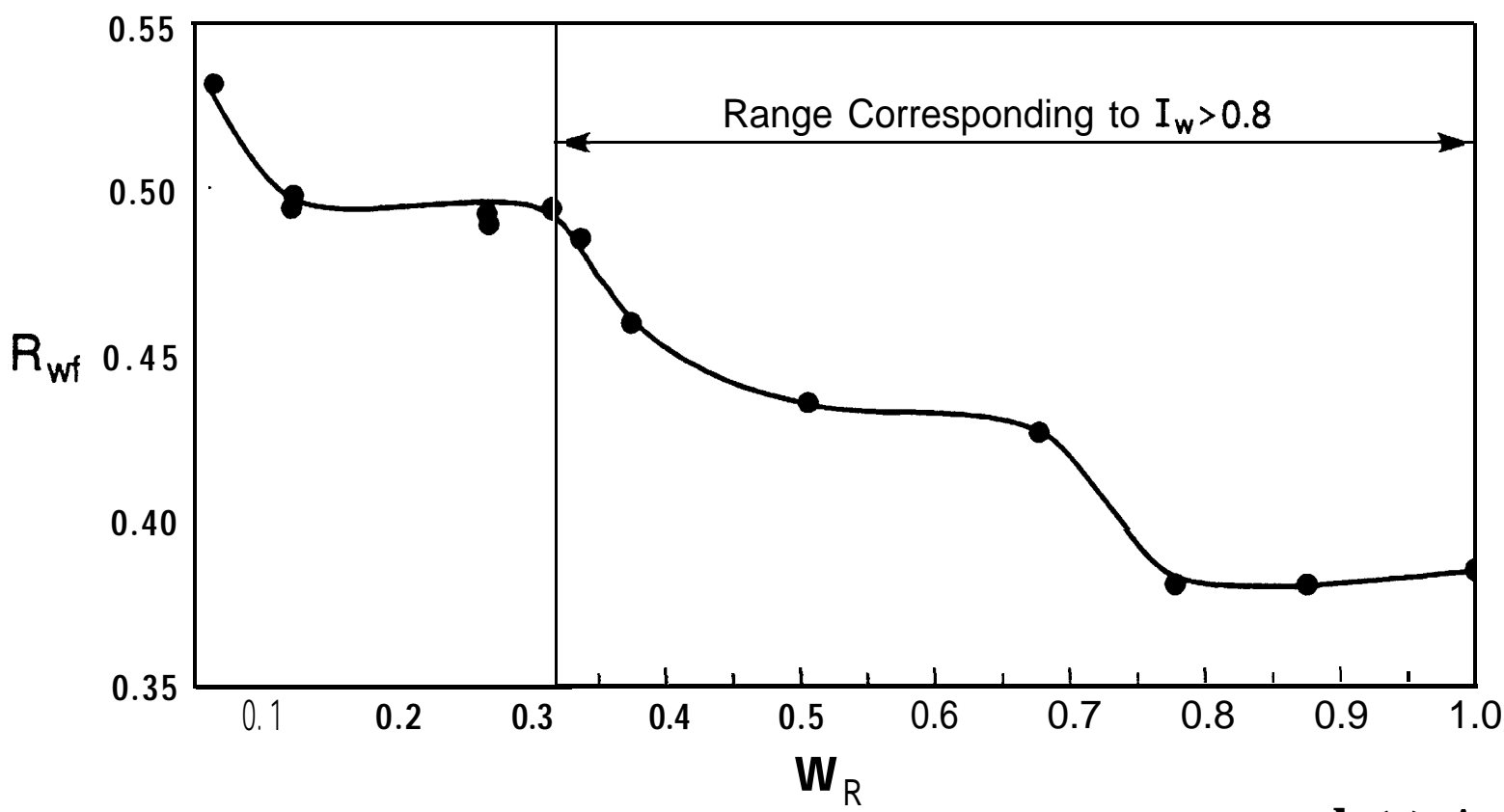

(b)

Figure 10. Relationships Between Waterflood Recovery and (a) Amott Nettability Index to Water and (b) Pseudo Relative Work of Imbibition 


\section{NOMENCLATURE}

$\begin{array}{ll}a & \text { constant relating } P_{C, p s} \text { with } t_{D} \\ b & \text { exponent of } t_{D} \\ C & \text { constant relating imbibition rate with time } \\ \text { I } & \text { Amott wettability index } \\ k & \text { permeability } \\ \mathrm{L} & \text { length or characteristic length of core samples } \\ \mathrm{N}_{\text {USBM }} & \text { USBM wettability number } \\ \mathrm{P} & \text { pressure } \\ \mathrm{q} & \text { imbibition rate } \\ \mathrm{R} & \text { oil (or nonwetting phase) recovery, \% original oil in place } \\ \mathrm{S} & \text { saturation } \\ \mathrm{t} & \text { time } \\ \mathrm{T} & \text { temperature } \\ \mathrm{V}_{\mathrm{p}} & \text { pore volume } \\ \mathrm{W} & \text { pseudo work of imbibition }\end{array}$

\section{Greek}

$\begin{array}{ll}\Delta & \text { difference } \\ \theta & \text { contact angle } \\ \mu & \text { viscosity } \\ \Sigma & \text { area under capillary pressure curves } \\ \sigma & \text { interracial tension, IFT } \\ \phi & \text { porosity }\end{array}$

\section{Subscripts}

$\begin{array}{ll}\text { a } & \text { aging } \\ \text { A } & \text { advancing } \\ \text { AH } & \text { Amott-Harvey } \\ \text { C } & \text { capillary or characteristic } \\ \text { d } & \text { dynamic } \\ \text { D } & \text { dimensionless } \\ \text { E } & \text { equilibrium } \\ \text { f } & \text { flooding } \\ \text { i } & \text { initial } \\ \text { im } & \text { imbibition } \\ \text { o } & \text { oil } \\ \text { or } & \text { residual oil } \\ \text { ps } & \text { pseudo } \\ \text { R } & \text { relative } \\ \text { S } & \text { spontaneous } \\ \text { sww } & \text { strongly water wet } \\ \text { W } & \text { water }\end{array}$




\section{DISCLAIMER}

Mention of specific brand names or models of equipment is for information only and does not imply endorsement of any particular brand. 


\section{REFERENCES}

1. Amott, E.:"Observations Relating to the Wettability of Porous Rock," Trans., $A I M E$, v.216 (1959), pp.156-62.

2. Donaldson, E. C., Thomas, R. D., and Lorenz, P. B.: "Wettability Determination and Its Effect on Recovery Efficiency," SPEJ (March 1969), pp. 13-20.

3. J adhunandan, P.P. and Morrow, N. R.:"Effect of Wettability on Waterflood Recovery for Crude Oil/Brine/Rock Systems," paper SPE 22597, Annual Technical Conference and Exhibition of SPE, Dallas, Oct. 6-9, 1991.

4. $\quad$ Cuiec, L. E.:"Rock/Crude Oil Interactions and Wettability: An Attempt to Understand Their Interrelation," paper SPE 13211, SPE Annual Technical Conference and Exhibition, Houston, Sept. 16-19, 1984.

5. Morrow, N.R. and McCaffery, F. G.:"Displacement Studies in Uniformly Wetted Porous Media," in Wetting, Spreading and Adhesion, J.F. Padday (cd.) Academic Press, New York (1978), pp.289-319.

6. Salathiel, R.A.:"Oil Recovery by Surface Film Drainage in Mixed Wettability Rocks," J PT (Oct. 1973), pp.1216-24.

7. Fatt, I. and Klikoff, W.A.:"Effect of Fractional Wettability on Multiphase Flow through Porous Media," Trans. AIME, v.216 (1959), pp. 426-32.

8. Moore, T.F. and Slobod, R. L.:"The Effect of Viscosity and Capillarity on the Displacement of Oil by Water," Producer Monthly, Aug. 1956, pp.20-30.

9. Gatenby, W.A. and Marsden, S. S.:"Some Wettability Characteristics of Synthetic Porous Media," Producers Monthly, Nov. 1957, pp. 5-12.

10. Bobek, J . E., Mattax, C. C., and Denekas, M. O.: "Reservoir Rock Wettability Its Significance and Evaluation," Trans., AIME v.213 (1958), pp.155-60.

11. Denekas, M. O., Mattax, C. C., and Davis, G. T.:"Effect of Crude Oil Components on Rock Wettability," J PT (Nov. 1959), pp.330-33.

12. Leverett, M. C.:"Flow of Oil-Water Mixtures through Unconsolidated Sands," Trans. AIME, v.132 (1939), pp.149-71.

13. Rapoport, L.A.:"Scaling Laws for Use in design and Operation of Water-Oil Flow Models," Trans. AIME, v.204 (1955), pp.143-50. 
14. Mattax, C.C. and Kyte, J . R.:"I mbibition Oil Recovery from Fractured, WaterDrive Reservoirs," SPEJ (J une 1962), pp. 177-84.

15. J adhunandan, P.P. and Morrow, N. R.:"Spontaneous Imbibition of Water by Crude Oil/Brine/Rock Systems," In Situ, v.15 (1991), no.4, pp.319-45.

16. Bokserman, A.A., Zheltov, Y. P., Kocheshkov, A.: "Motion of I mmiscible Liquids in a Cracked Porous Medium," Soviet Phy. Doklad, Oct. 1964, pp.285-7.

17. Torsaeter, O., Kleppe, J ., and van Golf-Racht, T.: "Multiphase Flow in Fractured Reservoirs," in Advances in Transport Phenomena in Porous Media, J . Bear and M.Y. Corapcioglu (eds.), NATO ASI Series, Series E: Applied Sciences - No. 128, 1987, Martinus Nijhoff Publishers.

18. Schechter, D.S. and Zhou, D. :"Capillary Imbibition and Gravity Segregation: Interactions with Phase Equilibrium in Oil/Brine/Alcohol System," Chap. 3.4 in ScaleUp of MiscibleFlood Processes, Annual Report to US DOE Grant No. DE-FG21-89MC26253, J an. 1991.

19. Reis, J.C. and Cil, M.:"A Model for Oil Expulsion by Countercurrent Water Imbibition in Rocks: One-Dimensional Geometry," J . Pet. Sci. \& Eng. (Dec. 1993), pp.97-107.

20. Cuiec, L. E., Bourbiaux, B. J ., and Kalaydjian, F.J:"Imbibition in LowPermeability Porous Media: Understanding and Improvement of Oil Recovery," paper SPE 20259, the 7th Annual Symposium on Enhanced Oil Recovery, Tulsa, April 1990.

21. Blair, P.M. :"Calculation of Oil Displacement by Countercurrent Water Imbibition," SPEJ (Sept. 1964), pp.195-202.

22. Bourbiaux, B.J. and Kalaydjian, F. J.:"Experimental Study of Concurrent and Countercurrent Flows in Natural Porous Media," SPERE (Aug. 1990), pp.361-8.

23. Kisilenko, B.E. and Ryzhik, V. M.:"Experimental Study of the Effect of Relative Viscosities on the Rate of Countercurrent Capillary Impregnation of Porous Media," Zhurnal Prikladnoi Mekhaniki i Tekhnicheskoi Fiziki, v.8, no.1 (1967), pp.89-91.

24. Hamon, G. and Vidal, J.:"Scaling-Up the Capillary Imbibition Process from Laboratory Experiments on Homogeneous and Heterogeneous Samples," paper SPE 15852, SPE European Petroleum Conference, London, Oct. 20-22, 1986. 
ż5. Morrow, N.R.: "Physics and Thermodynamics at I mmiscible Displacement in Porous Media," Ind. Eng. Chem. (1970), v.62, pp.32-56.

26. Li, Y. and Wardlaw, N. C.:"The influence of Wettability and Critical PoreThroat Size Ratio on Snap-off," J . Colloid and Interface Sci. v.109, no. 2 (Feb. 1986), pp.461-72.

27. Morrow, N. R., Lim, H.T., and Ward, J . S.:"Effect of Crude-Oil-Induced Wettability Changes on Oil Recovery," SPEFE (Feb. 1986), pp.89-103.

28. Villard, J . M., Buckley, J . S., Morrow, N. R., and Gauchet, R.:"Wetting and Waterflood Oil Recovery of A Moderately Viscous Crude Oil," paper 9323, SCA Meeting, Aug. 9-11, 1993, League City, TX. 